\title{
If it bleeds, it leads? Changing death coverage in The New Zealand Herald
}

\begin{abstract}
Death has become more prominent in the news in the past four decades. Articles about a murder or accident, which in the past may have featured on page five or seven of daily newspapers, now often take up all of the front page of The New Zealand Herald. New categories have also emerged, including the threat of death or near death. This is evident from the increase in human interest stories which not only report the details of the incident but also capture emotion. This article follows the increased visibility of death stories on the front page of New Zealand's largest newspaper, The New Zealand Herald, and investigates how that coverage has changed over time. International scholars have examined the visibility of death in the media closely. However, research is sparse about exactly how this large body of work correlates with New Zealand print media. Therefore, this study aims to close this gap by using content analysis to discuss the prominence of death in The New Zealand Herald over four decades from the 1970s, and the reasons for increased coverage of threats of death or near death.
\end{abstract}

Keywords: death, fear, front page, human interest, newspapers, news values, New Zealand

\section{LYN BARNES and ELESHA EDMONDS Auckland University of Technology}

HETHER it is a car accident, a murder or a shark attack, death has become a
ready source of content in daily newspapers. It is increasingly easy to access,
involves minimal cost and is in constant supply.

Happy stories don't sell, we are told, and people want their tornados, collapsed walkways, big-cat attacks and crashed helicopter stories. The media is more than willing to supply them. Death sells. If it bleeds, it leads (Coleman, 2004, p. 6).

Hanusch (2010) contends that the development of mass media during the twentieth century led to a higher proportion of death stories.

News organisations are competing as never before for the attention of audiences. This supposedly leads to increasingly sensationalised news coverage, where the old motto when it bleeds, it leads rules (Hanusch, 2010, p. 13).

162 PACIFIC JOURNALISM REVIEW 21(1) 2015 
It appears that The New Zealand Herald is following the trend towards more sensational content. As the editor-in-chief, Shayne Currie, told a class of journalism students at Auckland University of Technology in 2012: 'Whatever can kill you will make the front page' (Barnes, 2013).

Newspapers exist to make money and so circulation must be first priority. Therefore, greater care is being taken to ensure that stories that sell take the lead in the newspaper. As Conboy and Steel (2008) argue, the primary goal of the paper is to produce readers rather than news. Therefore, editors must create a selection of news tailored for a particular readership to create profit and/or exert influence on that readership (p. 651).

This article reports on news coverage of death as it has evolved and changed in New Zealand over four decades (Figure 1). We first outline previous studies on death in the media and the role of the front page. Using content analysis the authors found clear themes emerging which suggest that New Zealand is not only following international trends but confronting dilemmas associated with sensationalism. The article also traces the death story from simple fact-based reporting to narrative-themed stories that are now commonplace.

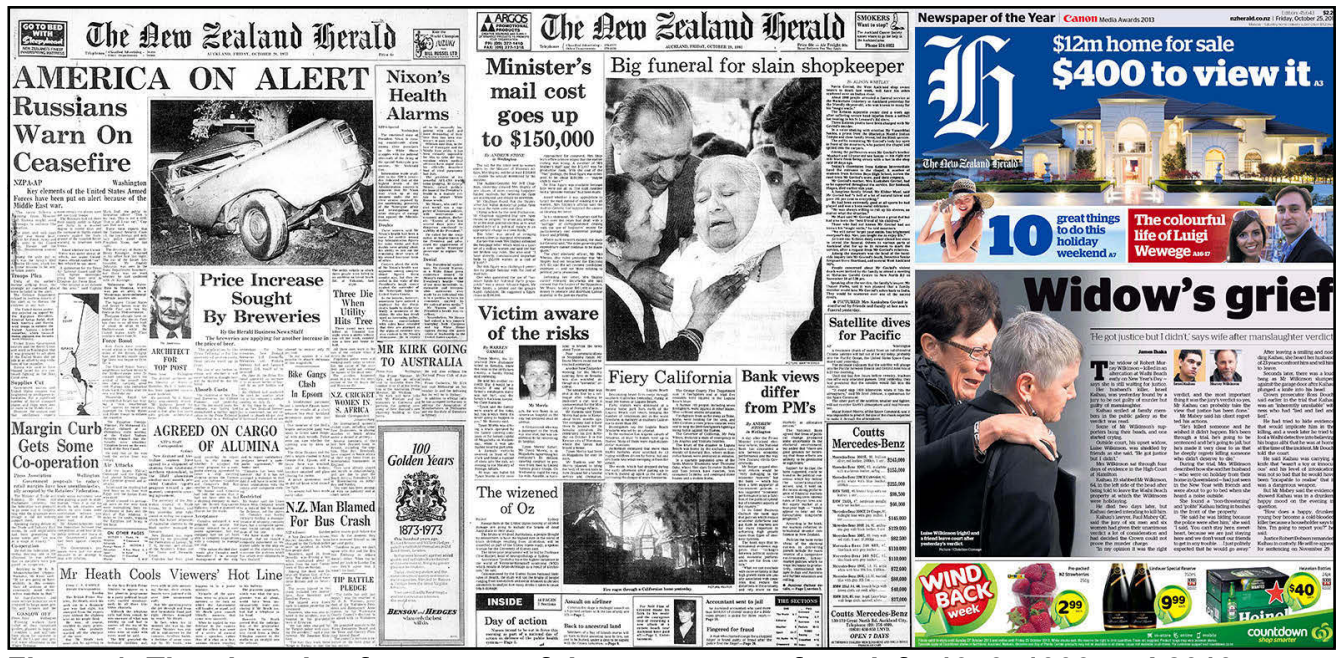

Figure 1. The changing front page of the newspaper, from left: 1973, 1993 and 2013.

\section{Scholarship of death}

A strong trend of many Western newspapers has been a move towards more sensational content, where trauma and grief have become news staples (Cote \& Simpson, 2006). Articles about death are now ubiquitous: they have been propelled to the front pages, sometimes replacing obituaries, which have consistently been run at the back of most newspapers (Barnes, 2012a).

The selection and organisation of news stories is often a hurried decision-making process because of the pressure to be first with the news. Galtung \& Ruge (1965) who proposed a list of news values to help in the selection process, included negative news, 
that which involves trauma or distress, as attractive to the reader. Masterton's (1998) updated version of news values adds support to this research. His theory suggests there are three core elements present for any information to be considered newsworthy: interest, timeliness and clarity. Stories about death are usually intriguing, easy to understand and are reported as soon as possible after they happen. As Walter, Littlewood and Pickering (1995) highlighted: 'The deaths boldly headlined and portrayed by the news media are extraordinary deaths. That is why they are so eminently story-worthy as news' ( $p$. 564). But deaths which make the news are not always extraordinary anymore. Even one fatality still provides enough content for a news story. Ultimately death draws on many news values beyond negativity, such as when the death is unexpected or happens to an ordinary person, or private citizen (Duncan, 2012).

As Rees (2004) points out, this is because it tells readers about threats that can affect them or their communities, and it can galvanise active responses that may reaffirm our sense that life has value. Walter et al (1995) suggest that readers may identify with the characters in a story whose emotional intensity and social vulnerability are being displayed 'not out of any macabre vicarious pain or voyeuristic pleasure, but as a reminder of their own mortality' (p. 586).

Tiffen's 2010 Australian study found little evidence in either frequency or prominence of stories to support the argument that news coverage had become more negative but concluded that there has been 'an increased emphasis on deaths by violent means' (p. 49). He suggests this leads to the media's reportage of death becoming less representational of the causes of death in real life. Comb and Slovic (1979) found newspapers overemphasised murders, accidents and crime but underemphasised deaths caused by disease.

Many scholars have examined the prominence of death in the mass media and how this has changed over the decades (Christensen, 2004; Hanusch, 2008; Moeller, 1999; Tiffen, 2006). While analysing the newsworthiness of stories that involve death, as well as the causes of death that were most reported, these studies offer an understanding of the ways in which death is approached by different areas of society. Hanusch (2008) provides an essential overview and thematic analysis of the large body of work that has been conducted on death in the media. He contends that death is extremely visible in the media, although historically this has not always been the case.

In Western societies, death was once a subject of taboo but it has now moved away from being a private matter and into the public arena. Death largely became more privatised by society during the twentieth century, therefore fewer people witnessed the process of death occurring and did not know what death looked like (Hanusch, 2010). He demonstrates that the media detected and filled that gap as it became more important for audiences who wanted death recognised. His theory supports the findings of Walter et al, who, after examining the deaths of 'peacetime private UK citizens', challenged the 'public absence of death' thesis by saying 'there is one arena that is very public and in which death makes a more-than-daily appearance: the mass media' (1995, p. 581).

164 PACIFIC JOURNALISM REVIEW 21(1) 2015 
Tiffen (2010) examined the coverage of death in Australian newspapers between 19652006. The papers included the major Sydney and Melbourne broadsheets and tabloids, two regional dailies and, in 2006, the national daily, The Australian. He noted that there was minimal change in the number of deaths reported in newspapers during this time, which he essentially attributed to a change in the size and presentation of the newspapers.

All papers have increased the relative proportion of stories of deaths stemming from crime, but the quality newspapers less than the other two, with the regional papers showing the sharpest increase. The differences between the types of papers should not be exaggerated, but the tabloids and regionals do have a more parochial set of priorities, and perhaps in their shorter stories present a more frightening view of the deaths occurring in the world. (p. 49).

This article extends Tiffen's research with a focus on New Zealand and specifically the front page of The New Zealand Herald, the country's largest metropolitan newspaper.

\section{Death in a New Zealand context}

The sample for this study was constructed by gathering the front page of The New Zealand Herald for two weeks over three different time periods and included all stories that involved death. Within the resources available, this sample allowed the researchers to analyse the evolution of front-page death stories over four decades using content analysis. Each year sampled was separated by a decade. The timeframe chosen was from October 18 to October 30 in the years 1973, 1993 and 2013. This meant 36 front pages were collected for analysis, including all weekly and Saturday publications of The New Zealand Herald. The fortnight period in October was a random two weeks at the end of the academic year. No deliberate time period was chosen to ensure the randomness of evidence, making the comparison of decades possible.

This qualitative analysis revealed definite trends in how death is now covered in The New Zealand Herald. A quantitative analysis could not be carried out with any degree of accuracy because of the change in the number of stories that featured on the front page of the newspaper but it did identify trends. The New Zealand Herald adopted a tabloid format in 2012 and, although the editor claimed it did not mean the editorial would reflect the new shape, it is clear that the front page of the newspaper has changed, not only in content but in composition. For example, in 1973, the front cover averaged 12 stories; in 2013, there is generally only one feature story. The authors agreed that in order to identify the evolution of change in death coverage, the number of stories that clearly covered someone's demise should be divided by the average number of stories featured on the front page.

Each front-page story that reported the death of at least one person is categorised under one of the following headings: Natural causes, accident, crime, natural disaster, political turmoil, anniversary of death, court case or coroner report and funerals. Initial 
data gathering made it apparent that another table of sub-categories should be developed to allow for the examination of other patterns within the selected stories. The category titles, or clear themes to emerge, were: Children, suicide, romance, photos and international/foreign news.

Another trend that became apparent as analysis progressed was the 'threat of death' or 'near-death' articles. These categories were deliberately separated from these figures because it was obvious that there was an increase in the number of stories in which a person was at risk of death and either survived or could still die.

Using content analysis, it was necessary to look for themes to build a picture of the patterns which emerged in the coverage of death over the past four decades. This form of methodology was chosen as some of the most sophisticated analyses in content analysis have been carried out with a focus towards news. It has been used 'for decades as a microscope that brings communication messages into focus' (McMillan, 2000). Examples of content analyses include a Canadian study of the portrayal of mental illness in Canadian newspapers (Day \& Page, 1986) and determining if the coverage of female and male athletics was a function of the gender of the sports newspaper personnel (Whisenant \& Schneider, 2003).

Krippendorff found empirical inquiries into communication content that dates back at least to the 1600 s when newspapers were examined by the church because of its concern about the spread of non-religious matters. Krippendorff identified four advantages of content analysis: it is unobtrusive; it accepts unstructured material; it is context sensitive and it can cope with large volumes of data. With newspapers, maximum sampling efficiency involved sampling procedures, for example, simple random sampling or constructing a week to represent all days of the week or selecting a convenient sample of seven consecutive days, as well as sample size.

In 1951, Stempel examined front cover photographs in a six-issue-a-week (no Sunday edition) of the Wisconsin newspaper. He found 12 days - two constructed weeks - sufficient to represent the year, and suggested that increasing sample size could be a poor investment of a researcher's time.

Using a similar sampling procedure, content analysis allowed the researchers to gather material that could be clustered together according to different categories for interpretation of the data across decades. Examining the changes and consistencies in news coverage then provided insight into the changing nature of new values and priorities of the news.

\section{Definition of categories}

Categories that emerged for the study were each defined to ensure consistency: a death by natural causes was defined as a death attributed primarily to illness, age or anything not influenced by external forces. An accident was an unexpected and unintentional event that resulted in death. A crime story was determined as intentional harm caused, which resulted in death and would be classed as a criminal act under New Zealand

166 PACIFIC JOURNALISM REVIEW 21(1) 2015 
law. Political turmoil was defined as death caused by war, protests and political unrest, for example, civil war. Anniversary of death included articles that were a follow-up or memorial of the event of death-this included aspects such as book releases about the death. A story about death that revolved around a court case, police investigation or coronial inquest story was defined as civil or criminal legal proceedings following death or investigation surrounding the death of a person. Finally funerals encompassed stories about any ceremony or service held after a person's death.

The sub-categories were also defined as followed: a story categorised as children referred to the death of a child (person between $0-16$ years) or if a child/ren was directly affected by the death of the deceased. Suicide was defined as death caused intentionally by the deceased. Romance referred to stories of death that focused on the deceased's relationship with a lover, partner or spouse. The category photo included was defined as when a death story was illustrated by a photograph. The foreign category was defined as death that occurred outside of New Zealand, including New Zealanders who died overseas.

\section{Broadsheet to tabloid}

A total of 37 stories were collected during the research time frame which mentioned the death of at least one person. Initial calculations showed a decrease from nine stories about death to six stories in 1973 and 2013 respectively. Furthermore, data from 1993 showed a significant outlier of 22 death stories reported (Tables 1,2). However, further analysis acknowledged that this was a result of a change in the total number of stories featured

\begin{tabular}{|c|c|c|c|}
\hline & 1973 & 1993 & 2013 \\
\hline Natural causes & - & - & - \\
\hline Accident & 4 & 9 & 4 \\
\hline Crime & 1 & 4 & - \\
\hline Natural disaster & - & 1 & - \\
\hline Political turmoil & 1 & 3 & - \\
\hline Anniversary of death & 1 & - & 1 \\
\hline Court case/Coroner & 2 & 4 & 1 \\
\hline Funerals & - & 1 & - \\
\hline Total & 9 & 22 & 6 \\
\hline Average no. of stories ${ }^{1}$ & 12 & 8.1 & $1.45^{2}$ \\
\hline To average no. of deathstories & 0.75 & 2.7 & 4.1 \\
\hline
\end{tabular}

Note: Death only - Excludes stories that allude to threat of death, i.e. rescues, near deaths, sickness.

1. Number of stories featured on the front page. In regards to 2013 this is a story that features on front page with sub-heading and heading and is not a contents box.

2. Stories are classified as text of more than two paragraphs. 


Table 2: Death reports sub categories
\begin{tabular}{|l|c|c|c|}
\hline & 1973 & 1993 & 2013 \\
\hline Children & 3 & 3 & 3 \\
\hline Threat of death & 4 & 4 & 3 \\
\hline Suicide/taboo & - & 1 & - \\
\hline Romance & - & 2 & 8 \\
\hline Prominent/elite figures & - & - & - \\
\hline Photo included & 1 & 4 & 9 \\
\hline International/foreign news & 4 & 8 & 1 \\
\hline
\end{tabular}

on the front page of The New Zealand Herald and that it was impractical to compare like with like. But an estimate shows that by dividing the total number of stories by the average number of stories, featured on the front page during the research period, decreased from an average of 12 stories in 1973 to an average of 1.45 stories in 2013. When these figures were taken into account, the average number of death stories increased from 0.75 in 1973, to 2.7 in 1993 and then almost doubled to 4.7 in 2013. This signalled that the number of stories that feature death on the front page of The New Zealand Herald has risen approximately by 3.95 stories over the last four decades.

This analysis also highlighted the fact that there was an obvious increase in the number of unexpected and tragic deaths: 66 per cent of the stories analysed from 2013 were categorised as an accident, which was an increase from 44 per cent in 1973 - signalling a rise in the prominence of reporting on unexpected deaths. Death by natural causes, such as illness and old age — which is a significant cause of death in society — was unrepresented in the sample as no stories on the front page covered the topic. This was expected as Tiffen's (2006) research of newspapers between 1956 and 2006 alluded to the point that frequent causes of death stayed stable, whereas unexpected causes of death, particularly stories related to violence and crime, doubled over the research period.

\section{Facts-based to narrative-themed}

A vast amount of research surrounding death in the media is geographically limited and does not offer data that can be analysed from a New Zealand angle. New Zealand's representation of death in the media is of great interest due to the country's small population and geographical size. New Zealand has been described as one of the world's most intimate countries with only two degrees of separation - a local colloquial theory that draws upon Frigyes Karinthy's (1929) idea of six degrees of separation. The idea proposes that everyone on earth is connected through a chain of up to five acquaintances. A variation of this idea has been adopted by many in New Zealand, including a national mobile company, in order to describe how interwoven relationships can be in New Zealand society.

168 PACIFIC JOURNALISM REVIEW 21(1) 2015 
Large news stories often draw interest due to a connection the reader may have with the subjects or the proximity of the event. Therefore negative news stories involving death, or an extraordinary death, often affect a wide range of New Zealanders due to our limited connections and the increased likelihood of a connection with the deceased. For example, a story about a dying doctor's wish to survive to see the birth of his first child made the front page on 24 October 2013. The likelihood of others knowing the family or identifying with the family was highly likely, which made this human interest story popular.

Masterton (1998) alludes to the evolution of the newspaper and the representation of death by pointing out changes in news values; he suggests the increase in the prominence of human interest stories as a news value in its own right. 'Human interest' is defined by Masterton as people wanting to know about other people and this includes 'almost anything which stirs human emotion in any way' (p. 97). Human interest stories have always had an appeal and are usually the first read (Masterton, 1998). But as newspapers have moved away from breaking news stories, now that the internet is immediate, and newspapers take time to print and distribute, there has been a move away from fact-based stories to more narrative-style stories (Duncan, 2012). These articles are written in a way in which the reporter is the narrator and provides emotional engagement for the reader (Duncan, 2012). For example, rather than 'A 30-year-old farmer was killed when his tractor overturned...' the article may begin with 'Father of three Darren Smythe died after his tractor overturned... This is a more personal narrative which reflects on respectable character or the futility of the death.

This increase in the human interest angle, or narrative, may also account for the notable number of articles involving romance. In 2013, 53 percent of the stories regarding death, or threat of death, involved a reference to the relationships of the deceased or victim. For example, the young doctor who was likely to die of cancer before his first child is born. The narrative follows the age-old tale of a young hero facing early death, again supporting Duncan's identification of the futility of death (2012, p. 595). This style of narrative also reinforces societal values (Brewer, 2009) as 'we reflect on our own value-laden beliefs, and make moral or ethical judgements on the characters we hear about' (p. 171).

Subsequently the narrative provides context to tragic events (Duncan, 2012) as well as enabling the reader to associate with the story. It does this by allowing readers to think they understand the motivations of the characters in the story and the details of their relationships (Brewer, 2009). In many ways it creates a 'like us' factor, where readers identify with the experiences and 'reinforce the emotional authenticity expressed within the story' (Duncan, p. 592). Brewer (2009) uses social contructivism to carefully analyse a number of articles in women's magazines which she argues are embedded with societal expectations. She concludes that people in the articles are 'presented to us in caricatures, as stock characters, not unlike some of those in the fairy stories of the Brothers Grimm' (p. 182). This was evident in the Romeo and Juliet themed story of the death of two people who drowned at Auckland's Muriwai beach. The New Zealand Herald ran with 
the headline 'Lovers die in failed rescue' (27 October 1993) in a bid, it would seem, to narrate the failed rescue as a fairy-tale-like tragedy.

The change from facts to narrative-themed stories can be illustrated by a $1993 \mathrm{New}$ Zealand Herald story about a babysitter accused of murdering two young girls (October $23,1993)$. The story, although featured on the front page, focused solely on the facts of the case and contained no narrative elements. Based on the findings in this article, if the story were run now it would have been a full front-page feature that painted a picture of the babysitter and the young girls, stirring emotions so readers could associate with the story, by questioning the motivation of a supposedly trustworthy figure.

The infrequency of death in society may also explain the fear factor that has emerged from the data which is labelled as the 'threat of death' (Coleman, 2004). Although there must always have been fear of impending or inevitable death, it was clearly not played up by the media decades ago. As Combs and Slavic (1979) demonstrate, 'heavy reporting of homicides and accidents as news probably occurs not only because it sells more newspapers, but because these hazards represent sources of societal vulnerability about which people need to be informed so that they can take precautions or institute appropriate controls' (p. 824).

It begs the question, however, as to why is it now that death has become more sensationalised and used to achieve such an emotional response from the reader? It could be assumed that a decline in the prominence of death in day-to-day lives, due to longer life expectancies, makes death more surprising and almost detached from the daily lives of the newspaper reader. This aspect deserves further investigation, particularly when it comes to the psychological point-of-view behind a reader's response or interest in stories regarding death.

Another obvious difference in the representation of death, that became apparent over the period studied, was the increase in the number of stories with an accompanying photograph. All front-page stories in 2013 were accompanied by a picture, which was not the case in previous decades. In 1983 photographs accompanying stories were very uncommon and it was rare to see so much as a head shot featured. There are a number of possible reasons for this: photographs, which were once an expensive option as they took up space that was once filled by columns of text, are now relatively cheap to include due to technological advancements. Photographs can now be taken by the journalist or even a citizen journalist, then emailed, placed and cropped on the page within minutes. This offers an element of immediacy which is vital in the newspaper industry which is competing against the accessibility of news stories and news images on the internet (Conboy \& Steel, 2008).

Images play a vital role in the narrative of a news story: As with the colour illustrations in a child's book, a photograph tells its own story. However, reliance on images to narrate a story is of concern, particularly when it comes to the visibility of death. Hanusch (2008) raised this issue when studying the prominence of images to portray

170 PACIFIC JOURNALISM REVIEW 21(1) 2015 
death in the media. While the study concluded that visible death is still largely absent, he noted that the treatment of death had changed over the years and the 'small amount published in today's newspapers may in fact be higher than, say, 50 years ago' (p. 316). Further research would be beneficial in comparing the change in the visual representation of death over the years.

Another interesting observation from this research is the decrease in the number of stories related to death from foreign sources appearing on the front pages. There could be a number of reasons for this. Part of the explanation is the new layout of The New Zealand Herald and the introduction of a world news section which specialised in foreign news. It also follows the increased independence of New Zealand as an economic entity. The New Zealand Woman's Weekly followed a similar pattern, of replacing foreign celebrities on its covers with local celebrities, as part of the move towards 'celebrating our own' (Barnes, 2013b).

It is also worth noting that the timeframe chosen for this sample focuses on only 12 days a year, which is a limited basis for generalising. Yet clear trends did emerge. The researchers agreed that to ensure findings were reliable, the samples should be taken from the same time period each year. A further study could compare different time periods and over a longer timeframe.

\section{Conclusion}

This article has established that death has evolved to become a prominent feature on the front page of The New Zealand Herald over the last four decades. The number of stories involving death increased from 0.75 in 1973 and virtually doubled to 4.7 in 2013, although this figure does not compare like with like. The transition from the broadsheet and tabloid newspaper has made this trend progressively obvious, even as the number of stories occupying the front page dropped from an average of 12 stories in 1973 to 1.45 in 2013.

The way the death story is told has also changed in the Herald, from fact-based articles that simply report the facts - who, where, when, why and how - to narratives that capture emotions and feelings, reflecting the age-old entertainment value of a good story which features villains and heroes, and reinforcing societal values that good wins out. To make these articles all the more appealing and personable, strong imagery appears to have become the deciding factor in news selection.

\section{References}

Barnes, L. (2013). Good grief: The death of the obituary. TEXT Special Issue 21, October 2013. Available at www.textjournal.com.au/speciss/issue21/Barnes.pdf

Brewer, R. (2009). The goss on Paul and Heather: Attitudes to celebrity and divorce in three NZ women's magazines. Pacific Journalism Review, 15(1), 169-185. 
Coleman, L. (2004). The copycat effect: How the media and popular culture trigger the mayhem in tomorrow's headlines. New York: Simon and Schuster.

Combs, B. \& Slovic, P. (1979). Newspaper coverage of causes of death. Journalism Quarterly, 56(4), 837-849.

Conboy, M. \& Steel, J. (2008). The future of newspapers: Historical perspectives. Journalism Studies, 9(5), 650-661. doi: 10.1080/14616700802207540.

Day, D.M. \& Page, S. (1986). Portrayal of mental illness in Canadian newspapers. Canadian Journal of Psychiatry, 31(9), 813-817.

Duncan, S. \& Newton, J. (2010). How do you feel? Preparing novice reporters for the death knock. Journalism Practice, 4(4), 439-53.

Duncan, S. (2012). Sadly missed: The death knock news story as a personal narrative of grief. Journalism, 13(5), 589-603.

Galtung, J. \& Ruge, M. (1965). The structure of foreign news. Journal of International Peace Research, 2(1) 64-91.

Hanusch, F. (2008). Graphic death in the news media: present or absent. Mortality, 13(4), 301-317. Hanusch, F. (2010). Representing death in the news: Journalism, media and mortality. Basingstoke, UK: Palgrave Macmillan.

Kitch, C. (2000). A news of feeling as well as fact: Mourning and memorial in American news $\neg$ magazines. Journalism, 1(2), 171-19. doi: 10.1177/146488490000100202

McMillan, S. J. (2000). The microscope and the moving target: The challenge of applying content analysis to the world wide web. Journalism \& Mass Communication Quarterly, 77(1), 80-98. doi: $10.1177 / 107769900007700107$.

Masterton, M. (1998). A theory of news. In M Breen (Ed.) Journalism: Theory and Practice (pp. 85-103.). Macleay Press: Sydney,

Neuendorf, A. K. (2002). The content analysis guidebook. Thousand Oaks, CA: Sage Publications. Rees, G. (2013). The trauma factor. In K. Fowler-Watt and S. Allan. (Eds.). Journalism's New Challenges.

Reisner, E. A. (1992). The news conference: How daily newspaper editors construct the front page. Journalism and Mass Communication Quarterly, 69(4), 971-986.

Simpson, R. \& Cote, W. (2006). Covering violence: A guide to ethical reporting about victims and trauma. New York: Columbia University Press.

Tiffen, R. (2006). Death in the news: 1956-2006. Australian Journalism Review, 32(1), 41-50. Walter, T., Littlewood J. \& Pickering, M. (1995). Death in the news: The public invigilation of private emotions. Sociology, 29(4), 579-596.

Whisenant, W. \& Schneider, R.G. (2003). Research and reviews using a content analysis to examine the gendering of sports newspaper personnel and their coverage. Journal of Sport Management, 17(4), 376-393.

Lyn Barnes is a senior lecturer in journalism, enrolled in a doctorate in Communication Studies. Lyn Barnes: lyn.barnes@aut.ac.nz

Elesha Edmonds is a postgraduate student at AUT University completing an honours degree in Communication Studies. 